\title{
Topological and biomass balance approaches to analyzing food webs of Bahía Magdalena, Baja California Sur, Mexico
}

\author{
V. H. Cruz-Escalona ${ }^{1,4}$, A. F. Navia ${ }^{1,2}$, P. A. Mejia-Falla², M. V. Morales-Zárate ${ }^{3}$ and
}

C. A. Salinas-Zavala ${ }^{3}$

${ }^{1}$ Instituto Politécnico Nacional, Centro Interdisciplinario de Ciencias Marinas (IPN-CICIMAR), Apartado Postal, 592, La Paz, Baja California Sur, México, CP 23094

${ }^{2}$ Fundación colombiana para la investigación y conservación de tiburones y rayas-SQUALUS-, Carrera 60A No 11-39, Cali, Valle, Colombia

${ }^{3}$ Centro de Investigaciones Biológicas del Noroeste, Av. Instituto Politécnico Nacional No. 195. Col. Playa Palo de Sta. Rita Sur, Apartado Postal 128, La Paz, Baja California Sur, México, CP 23096

${ }^{4}$ Corresponding author: Víctor Hugo Cruz Escalona. Centro Interdisciplinario de Ciencias Marinas, Instituto

Politécnico Nacional. Departamento de Pesquerías y Biología Marina. Av. IPN s/n. Col. Playa Palo de Santa Rita. C.P. 23096. La Paz,Baja California Sur, México.Email: vescalon@ipn.mx or vicreshu@gmail.com.Telephone: +52 (612) 12-25344. Fax number: +52(612) 122-53-22

Keywords: Centrality index, Ecopath model, Keystone index, Node degree.

\begin{abstract}
In this paper, we used two methodological approaches to analyze the structure and function of a trophic web in the temperate coastal lagoon of Bahía Magdalena, Baja California Sur, Mexico, which represents the largest wetland ecosystem along the west coast of the Baja California peninsula. Ecosystem structure was studied using a topological approach, while ecosystem functioning was analyzed using a biomass balance model. Connectance values indicated a low number of functional group interactions, consistent with the range proposed for similar marine trophic webs. This pattern may reflect incorporation of a few functional groups clustered along the trophic web. Results would vary if the model included more functional groups or different levels of aggregation, since aggregation and diversity strongly influence the base of the food web. Topological results suggest that trophic web structure depends primarily on lower and intermediate trophic level organisms like macrobenthic invertebrates, penaeid shrimp and marine turtles. Balance biomass model results suggest that trophic groups positioned on the first level most strongly support Bahía Magdalena trophic web functioning. In particular, the pelagic red crab (Pleurocondes planipes) transfers energy between basal and upper levels of the food web (a wasp-waist energy control). When compared to ecosystems at different latitudes, the results indicate that the Bahía Magdalena ecosystem is still in a developmental phase, wherein trophic web functioning depends largely on the balance between energy flows originating from primary producers and those originating from detrital pathways. While these results are preliminary, they demonstrate the potential of combined topological and biomass approaches in analyzing highly organized ecosystems. The combined approach can make both theoretical and empirical predictions about the functional response of real systems to structural changes, thus enhancing evidence-based methods for ecosystem management.
\end{abstract}

Abbreviations: ALP - Average Length of the Pathway, BC - Betweenness Centrality; CC - Closeness Centrality, KPP - Key Player Problem.

\section{Introduction}

Trophic web studies typically describe general ecological patterns, such as structure and organization (Dunne 2009). Recent methodological advances have renewed interest in general ecological studies such as the diversity-stability relationship or the role of keystone species in food webs, and encouraged more systems-level analysis of how networks function. These analyses include the evaluation of the role of the species and topological properties in the stability of the networks (Gaichas and Francis 2008, Navia et al. 2010, 2012, 2016).

Trophic web approaches assume that each species in an ecosystem relates to others through a complex network of di- rect and indirect trophic interactions (Bascompte et al. 2005) Trophic web analysis can reveal structural and functional patterns that in turn demonstrate relationships between complexity and ecological stability (May 1972, Pimm 1982, Dunne 2006, 2009). Some of these approaches attempt to identify key species, sets of key species, and species of topological relevance, or functional groups that stabilize trophic webs (Libralato et al. 2006, Jordán et al. 2008). In this regard, some studies have found that loss of species, for example by fishing mortality, can exert strong ecological effects on the web (e.g., Lotze et al. 2011, Navia et al. 2012, 2016).

Numerous approaches have been developed to study the trophic webs of Mexico's marine ecosystems. Most have used biomass balance models (Ecopath) as an approximation tool 
focusing on the description of trophic webs and flows (e.g., Zetina-Rejón et al. 2003, Cruz-Escalona et al. 2007). Many of the marine trophic webs described by these studies experience anthropogenic impacts such as overfishing and pollution, which have modified structural and functional features thus altering the original trophic structure (Morales-Zárate et al. 2004).

While the influence of predators on species, populations, communities, and ecosystems is fairly well documented, the predictability and strength of this influence are still under investigation. Studies have sought to investigate the relative importance of and variation in the top-down influence of apex predators, and the extent to which certain patterns apply across different ecosystems (Estes et al. 2001). Nonetheless, understanding whether ecosystem function is controlled by trophic cascades involving a few key species or by a greater complexity of food web interactions within and across systems (Polis and Strong 1996) is a controversy that remains unresolved (Estes et al. 2001).

The complexity of marine food webs results in difficulties in the identification and understanding of the interactions and dynamics that determine performance. Therefore, it is important to integrate different available approaches to study the processes that must be protected to preserve food webs. Despite this, most studies, especially those aimed at ecosystem-based management, focus only on the structure (Navia et al. 2016) or function (Heymans et al. 2014) of food webs, and few studies have attempted to integrate structural and functional perspectives to construct a more holistic approach to trophic webs (Jordán et al. 2008). Therefore, this research used two different methodological approaches to analyze the structure and functioning of the trophic webs operating in Bahía Magdalena, the largest wetland ecosystem along the west coast of the Baja California peninsula, Mexico. Methods included topological analysis and organic matter flows estimated using the balance-biomass Ecopath model.

\section{Materials and methods}

\subsection{Study area}

Bahía Magdalena is part of the Bahía Magdalena-Almejas lagoon complex (Fig. 1), and represents the largest wetland ecosystem $\left(\sim 1200 \mathrm{~km}^{2}\right)$ along the west coast of the Baja California peninsula, Mexico. The Bahía Magdalena lagoon covers $565 \mathrm{~km}^{2}$ with a total water volume (low-high tide) of $6.8-8.1 \mathrm{~km}^{3}$ (Funes-Rodríguez et al. 2007). The lagoon is separated from the Pacific Ocean by Margarita and Magdalena Islands, and sand bars protect the lagoon from ocean swells (Cervantes-Duarte et al. 2013). The area is typically regarded as the boundary between temperate conditions modulated by the California Current and subtropical conditions. The region thus marks the southern geographic limit of many temperate species, especially shallow water invertebrates (CervantesDuarte et al. 2013). From an ecological perspective, Bahía Magdalena is considered a Biological Activity Center (BAC), hosting up to four times the primary and secondary productivity of surrounding coastal areas (Funes-Rodríguez et al. 2007). Species of commercial and ecological importance occur in high density around the study area, and their distribution enhances diversity of bordering ecosystems as well (Lluch-Belda et al. 2000). Given its biological and economic importance, numerous multidisciplinary studies have been conducted on Bahía Magdalena over the past 40 years, including the physical-environmental framework and the biology and ecology of different taxonomic groups, in particular fishery resources (Funes-Rodríguez et al. 2007).

\subsection{Topological model (structural perspective)}

Food webs have been constructed from information on food sources and ecological traits of species in the Bahía Magdalena ecosystem (see Cruz-Escalona et al. 2013 for more details). Topological analysis of the trophic web in the study areas assumed a binary presence/absence matrix for interactions among 24 functional groups/species. Local and intermediate scale network indices (see below) were used to assess the positional importance of these different nodes, as were ecological features derived from information theory using UCINET VI (Borgatti et al. 2002).

\subsubsection{Local and global indices}

Connectance $(C)$ refers to the proportions of interactions that are realized within a trophic web compared to all possible interactions. It is calculated as

$$
C=\frac{2 L}{N(N-1)}
$$

where $L$ is the number of observed interactions and $N$ is the number of nodes in the web; the formula excludes cannibalism and considers undirected links.

Node degree $(D)$ is the number of other nodes connected to node $i$. The degree of a node $i\left(D_{i}\right)$ is the sum of prey (indegree, $D_{\text {in }}$ ) and predators (out-degree, $D_{\text {out }}$ ), which is calculated as

$$
D_{i}=D_{i}+D_{\text {out }}
$$

This property is relatively simpler but less informative than other properties.

Node centrality is typically measured using two different indices. The first is based on intermediation of nodes and is referred to as betweenness centrality $(B C)$. This index measures how often a node $i$ participates in the shortest path between each pair of nodes $j$ and $k$ (Borgatti et al. 2002). The standardized betweenness centrality for node $i$ is:

$$
B C_{i}=\frac{2 \times \sum_{j \leq k} g_{j k}(i) / g_{j k}}{(N-1)(N-2)}
$$


where $i \neq j$ nor $k, g_{j k}$ is the shortest number of equal steps between nodes $j$ and $k$, and $g_{j k}(i)$ is the number of steps in which node $i$ is incident ( $g_{j k}$ could be equal to one). The denominator is two times the number of pairs of nodes, not counting $i$. This ratio measures node centrality in how accessible it is, via the web's shortest steps. If a given trophic group has a high $B C_{i}$, the loss of this node (functional group) would significantly affect the trophic web.

The second centrality index applied is the 'closeness index' $(C C)$ or closeness centrality. Based on trophic proximity, this index quantifies the length of theminimumnumber of steps from a given node to all others. The standardized version $\left(C C_{i}\right)$ is:

$C C_{i}=\frac{N-1}{\sum_{j=1}^{N} d_{i j}}$

where $i \neq j$ nor $k$, and $g_{j k}$ is the shortest distance between nodes $i$ and $j$ in the web. A higher $C C_{i}$ value for a trophic group means that elimination of this group will affect a relatively larger proportion of other groups.

The keystone $\left(K_{i}\right)$ index characterizes the relative importance of a species in an ecosystem according to its position in the trophic web. Defined in detail by Jordán et al. (2006), this ratio considers nodes that are directly connected along with additional information. It is defined as follows:

$$
K_{j}=\sum_{c=1}^{n} \frac{1}{d_{c}}\left(1+K_{b}\right)+\sum_{e=1}^{m} \frac{1}{f_{e}}\left(1+K_{t}\right)
$$

where $n$ is the number of predators for species $i, d_{c}$ is the number of prey for this predator $c$, and $K_{b c}$ is the impor- tance ratio for predator $c$ from bottom to top (bottom-up). Symmetrically, $m$ is the number of prey among species $i, f_{e}$ is the number of predators for prey $e$ and $K_{t e}$ is the importance ratio from top to bottom (top-down), of the $e^{\text {th }}$ prey. Sums containing non-zero $K_{b c}$ and $K_{t e}$ values refer to indirect effects ( $K_{\text {indir }}$ ) while those with $K_{b c}$ and $K_{t e}$ terms equal to zero (i.e., $\left.\Sigma 1 / \mathrm{d}_{c}+\Sigma 1 / f_{e}\right)$ refer to direct effects $\left(K_{d i r}\right)$.

In addition to providing information on the number of connections between nodes, this ratio evaluates how neighbors connect (Jordán et al. 2006), considering vertical but not horizontal interactions (e.g., trophic cascades vs. apparent competition). Likewise, the ratio characterizes the positional importance, distinguishing direct from indirect effects, and bottom-up from top-down effects within the trophic web (Jordán et al. 2006). This ratio was calculated using FLKS 1.1 software.

The 'Key Player Problem' (KPP) approach (Borgatti and Molina 2003) in general web analysis determines key ecosystem groups (defined as topological keystone species complexes by Jordán et al. 2006). This study used the Key Player Problem 2 (KPP-2) algorithm, which identifies k-players that are maximally connected to all other nodes, acting as a kernel in optimally distributing information throughout the network. Thus, KPP identifies those species that when removed from the network produce the greatest number of individual components (fragmentation).This analysis was performed using Key Player 1.1 software (Borgatti and Foster 2003).

We followed methodology in Scotti and Jordán (2010) to examine the relationships between index measurements and trophic levels in Bahía Magdalena. Specifically, we plotted each index against the unweighted version of trophic level

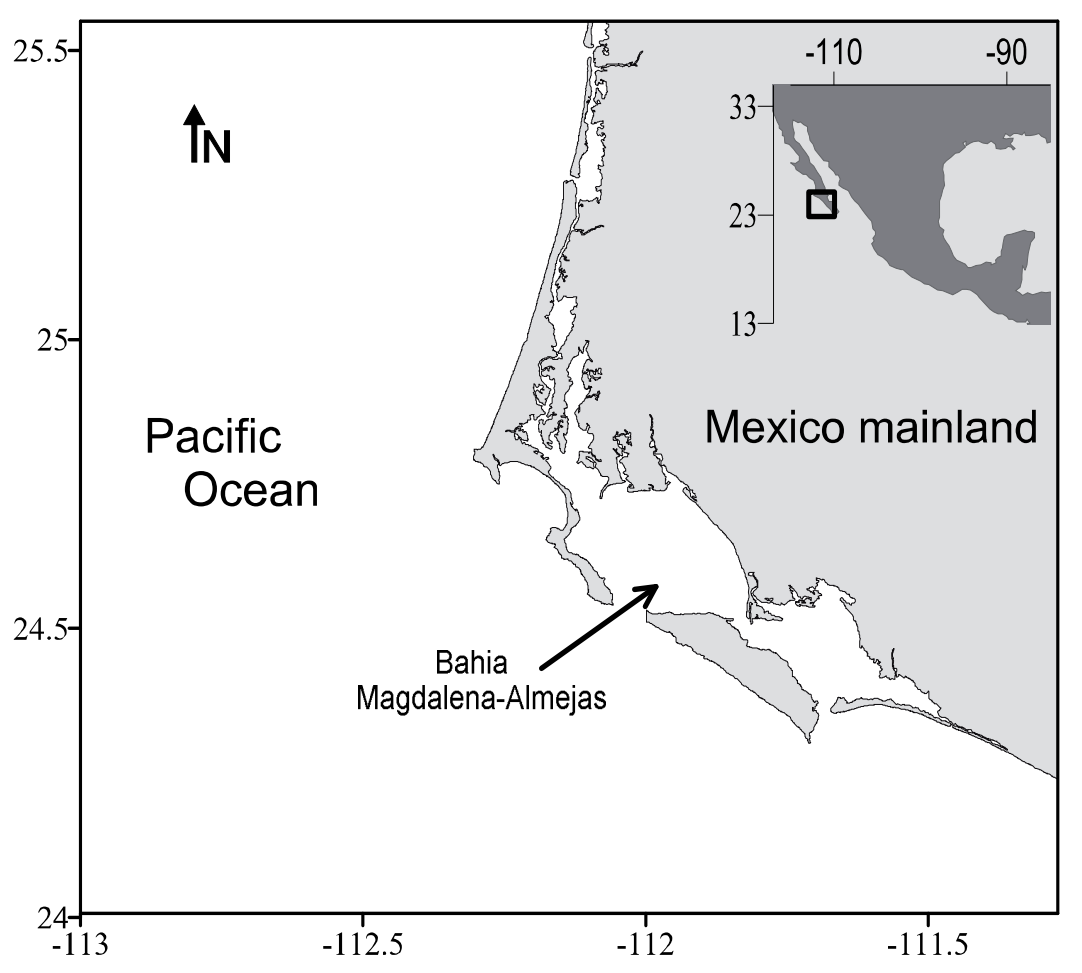

Figure 1. Bahía MagdalenaAlmejas is located along the Pacific coast of Baja California Sur, Mexico. 
(TL, Williams and Martinez 2004) in specific combinations ( $D$ vs. $T L ; B C$ vs. $T L, C C$ vs. $T L$ and $K$ vs. $T L$ ).

\subsubsection{Other structural attributes}

Foodweb 1-0 (Perdomo et al. 2012) freeware was used to estimate several metrics of the food web. We employed Foodweb 1-0 to estimate the fraction of basal, herbivorous, intermediate and top species. Each fraction is calculated relative to the total number of species in the food web. Basal species $(b)$ are those in level zero; herbivorous are those at level 1; top $(t)$ are those at the highest level (i.e., taxa which are not consumed by any other taxa included in the food web, $>4)$; and intermediate $(i)$ are those that are neither basal nor top (Pimm 1982). The total number of links ( $L$; calculated as the sum of all cells in the original food web matrix) and the linkage density $(L / S$; calculated by dividing the total number of links by the number of species) were also estimated (Pimm 1982). The prey:predator ratio $(b+1) /(t+1)$, which measures the shape of the trophic web (triangular indicates high values and square indicates low values) was calculated by dividing the total number of species that are either intermediate or basal by the total number that are either basal or intermediate (Hall and Raffaelli 1991); when the prey:predator ratio is $<1$, the trophic web exhibits an inverted structure that may indicate instability in the ecosystem. Finally, average length of the pathway $(A L P)$, defined as the average number of links in a food chain across a food web, was calculated.

\subsection{Biomass balance model (Ecopath: functional perspective)}

Ecopath models quantify the average organization of an ecosystem in terms of biomass and fluxes through the trophic web. The model aggregates and represents all species as ecologically connected functional groups (e.g., predators and prey) through a matrix of diet composition. Ecopath uses a mass-balanced food-web model, assuming that the production of one functional group is equal to the sum of all predation, non-predatory losses, exports, biomass accumulations, and catches, as expressed by the equation (Christensen et al. 2005):

$P_{i}=Y_{i}+B_{i} \cdot M 2_{i}+E_{i}+B A_{i}+P_{i} \cdot\left(1-E E_{i}\right)$

where $P_{i}$ is total production of group $i, Y_{i}$ is the total fishery catch rate of $i, B i$ is the biomass of the group $i, M 2_{i}$ is the instantaneous predation rate for group $i, E_{i}$ is the net migration rate (emigration - immigration), $B A_{i}$ is the biomass accumulation rate for $i$, and $P_{\mathrm{i}} \cdot\left(1-E E_{i}\right)$ is the "other mortality" rate for $i$. This formulation incorporates most of the production or mortality components in common use, perhaps with the exception of reproductive production (i.e., egg production). However, most reproductive production can be accounted for either in predation or other mortality. Thus, equation (6) can be re-expressed as:
$B_{i} \cdot(P / B)_{i} \cdot E E_{i}-\sum_{j=1}^{n} B_{j} \cdot(Q / B)_{i} \cdot D C_{i j}-Y_{i}-E_{i}-B A_{i}=0$

where: $P / B_{i}$ is the production/biomass ratio for $i$ and under most conditions corresponds to the total mortality rate, $Z$, commonly estimated as part of fishery stock assessments. $E E_{i}$ is the ecotrophic efficiency of group $i$, describing the proportion of the production that is utilized in the system, $Q / B_{i}$ is the consumption/biomass ratio of the predator $i$ and $D C_{i j}$ is the fraction of prey $i$ in the average diet of predator $j$ (Christensen et al. 2005). Ecopath requires data for three of the following four terms for each group of the model: Biomass $\left(B, \mathrm{t} \cdot \mathrm{km}^{-2}\right)$ for the year under consideration; Production/Biomass ratio $\left(P / B\right.$, year $\left.{ }^{-1}\right)$; Consumption/Biomass ratio $\left(Q / B\right.$, year $\left.{ }^{-1}\right)$; and Ecotrophic Efficiency ( $E E$, proportion); these terms indicate the unexplained mortality for each group. In addition, the diet composition is required as a contribution (in mass) of the prey items in the diet of each group (Christensen et al. 2005).

Ecopath with Ecosim (EwE) model parameterization allows characterization of trophic structure and energy fluxes in the ecosystem according to attributes defined by classical ecological theory. These are estimated for each functional group in the model. Cruz-Escalona et al. (2013) present a complete description of attributes derived from Ecopath models used to characterize the structure and functioning of the Bahía Magdalena trophic web. In this paper, we only include those that characterize the overall size of the ecosystem sensu Ulanowicz $(1986,2004)$, as well as others that we consider comparable to those derived from topological analysis. All attributes and indices used in this study are listed and described in Table 1 .

\section{Results}

\subsection{Topological model}

The analyzed trophic web presented 103 out of 529 possible interactions (excluding cannibalism), which resulted in a connectance value of 0.19 . According to node degree $(D)$ results, macrobenthic invertebrates represented the highest value node $\left(D_{\text {macrobenthic invertebrates }}=18\right)$, followed by sea lions $\left(D_{\text {sea lions }}=14\right)$, other crustaceans $\left(\mathrm{D}_{\text {other crustaceans }}=12\right)$ and penaeid shrimp $\left(D_{\text {penaeid shrimp }}=12\right)$. Rhodophyta, gray whales (Eschrichtius robustus) and Chlorophyta exhibited the lowest node degree values $\left(D_{\text {Rhodophyta }}=4, D_{\text {gray whales }}=2\right.$ and $D_{\text {Chlorophyta }}=1$; Fig. 2a).

Centrality indices showed that macrobenthic invertebrates have the highest betweenness values $\left(B C_{\text {macrobenthic invertebrates }}=\right.$ $43.2)$, followed by green turtles $\left(B C_{\text {green turtles }}=37.1\right)$ and sea lions $\left(B C_{\text {sea lions }}=14.2\right)$. Algae and gray whales showed the lowest betweenness values $\left(B C_{\text {Phaeophyta }}=1.5, B C_{\text {Rhodophyta }}=\right.$ $1.5, B C_{\text {Chlorophyta }}=0$ and $\left.B C_{\text {gray whales }}=0\right)$ (Fig. 2b). For measures estimating closeness of species $(C C)$, macrobenthic invertebrates $\left(C C_{\text {macrobenthic invertebrates }}=52\right)$, sea lions $\left(C C_{\text {sea lions }}=\right.$ $56)$ and penaeid shrimp $\left(C C_{\text {penaeid shrimp }}=58\right)$ gave the most representative values (Fig. 2c). 
Table 1. List of ecological indicators sensu Ulanowicz $(1986,2004)$ used to describe the functional attributes of the Laguna Bahía Magdalena Mexico model (modified from Heymans et al. 2014).

\begin{tabular}{|c|c|c|c|c|}
\hline Ecological indicator & Acronym & Units & Definition & Reference \\
\hline Total System Throughput & TST & $\mathrm{t} \cdot \mathrm{km}^{-2} \mathrm{y}^{-1}$ & $\begin{array}{l}\text { The sum of the all the flows through the } \\
\text { ecosystem }\end{array}$ & Ulanowicz 1986, 2004. \\
\hline Primary Production/TST & $\mathrm{PP} / \mathrm{TST}$ & - & $\begin{array}{l}\text { Primary production over the sum of all the } \\
\text { flows through the ecosystem }\end{array}$ & $\begin{array}{l}\text { Odum 1971; Christensen } \\
\text { et al. } 2005 .\end{array}$ \\
\hline Flows to Detritus/TST & $\mathrm{FD} / \mathrm{TST}$ & - & $\begin{array}{l}\text { Flows to detritus over the sum of all the } \\
\text { flows through the ecosystem }\end{array}$ & Christensen et al. 2005. \\
\hline Total consumption/TST & $\mathrm{Q} / \mathrm{TST}$ & - & $\begin{array}{l}\text { Total consumption over the sum of all the } \\
\text { flows through the ecosystem }\end{array}$ & Christensen et al. 2005 . \\
\hline Total respiration/TST & $\mathrm{R} / \mathrm{TST}$ & - & $\begin{array}{l}\text { Total respiration over the sum of all the } \\
\text { flows through the ecosystem }\end{array}$ & Christensen et al. 2005 . \\
\hline Total exportation/TST & $\mathrm{Ex} / \mathrm{TST}$ & - & $\begin{array}{l}\text { Total exportation of the system over the sum } \\
\text { of all the flows through the ecosystem }\end{array}$ & Christensen et al. 2005. \\
\hline $\begin{array}{l}\text { Production primary/Total } \\
\text { production }\end{array}$ & $\mathrm{PP} / \mathrm{PT}$ & - & Primary production over total production & Christensen et al. 2005. \\
\hline $\begin{array}{l}\text { Total Biomass (excluding } \\
\text { first trophic level) }\end{array}$ & TBco & $\mathrm{t} \cdot \mathrm{km}^{-2}$ & $\begin{array}{l}\text { Total biomass of the community excluding } \\
\text { detritus and primary producers }\end{array}$ & Christensen et al. 2005 . \\
\hline Ascendency/Capacity & $\mathrm{A} / \mathrm{C}$ & $\%$ & $\begin{array}{l}\text { Relative Ascendency, dimensionless index } \\
\text { of ascendency - index of organization of the } \\
\text { food web }\end{array}$ & Ulanowicz 1986, 2004. \\
\hline Overhead/Capacity & $\mathrm{O} / \mathrm{C}$ & $\%$ & $\begin{array}{l}\text { Relative overhead, dimensionless index of } \\
\text { the ecosystem's strength in reserve }\end{array}$ & Ulanowicz 1986, 2004. \\
\hline Finn's Cycling Index & FCI & $\%$ & $\begin{array}{l}\text { It quantifies the relative amount of recycling } \\
\text { and is an indication of stress and structural } \\
\text { differences either among models }\end{array}$ & Finn 1976. \\
\hline System Omnivory Index & SOI & $\%$ & Variance of the trophic levels in the diet & $\begin{array}{l}\text { Christensen and Walters } \\
2004 \text {. }\end{array}$ \\
\hline
\end{tabular}

Table 2. Network indices quantifying the positional importance of nodes (trophic entities or components) in the Bahía Magdalena ecosystem, with top predators included. Nodes are listed in order of decreasing importance, based on the $K$ index. $K=$ topological importance index; $K_{b u}=$ bottom-up importance, $K_{t d}=$ top-down importance, $K_{d i r}=$ direct effect importance index, $K_{\text {indir }}=$ indirect effect importance index.

\begin{tabular}{llllllll}
\hline Rank & Code & Node or Trophic Component & $K_{b u}$ & $K_{\text {td }}$ & $K_{\text {dir }}$ & $K_{\text {indir }}$ & $K$ \\
\hline 1 & Dolphins & Dolphins & 0.00 & 10.68 & 4.02 & 6.66 & 10.68 \\
2 & Sealions & Sea lions & 0.00 & 10.22 & 3.81 & 6.41 & 10.22 \\
3 & Phy & Phytobenthos & 7.08 & 0.00 & 2.38 & 4.70 & 7.08 \\
4 & Det & Detritus & 6.74 & 0.00 & 2.18 & 4.56 & 6.74 \\
5 & Macro & Macrobenthic invertebrates & 4.97 & 0.44 & 4.01 & 1.41 & 5.42 \\
6 & Zoo & Zooplankton & 3.81 & 0.24 & 1.61 & 2.43 & 4.04 \\
7 & S_bass & Sea bass & 0.16 & 3.78 & 2.13 & 1.81 & 3.94 \\
8 & M_tur & Marine turtles & 0.16 & 2.90 & 2.56 & 0.50 & 3.06 \\
9 & Ska & Rays & 0.16 & 2.19 & 1.46 & 0.89 & 2.36 \\
10 & SBFS & Small bottom feeding Sciaenids & 0.29 & 1.89 & 1.38 & 0.80 & 2.18 \\
11 & Seag & Seagrass & 1.96 & 0.00 & 1.23 & 0.73 & 1.96 \\
12 & O_crus & Other crustaceans & 1.10 & 0.68 & 1.51 & 0.28 & 1.78 \\
13 & P_shr & Penaeid shrimp & 1.10 & 0.68 & 1.51 & 0.28 & 1.78 \\
14 & Aba & Abalone & 0.85 & 0.85 & 1.49 & 0.22 & 1.70 \\
15 & Flat & Flatfish & 0.51 & 1.01 & 1.12 & 0.40 & 1.52 \\
16 & Echi & Echidoderms & 0.58 & 0.70 & 0.99 & 0.29 & 1.28 \\
17 & Pp & Pleuroncodes planipes & 0.72 & 0.54 & 1.05 & 0.21 & 1.26 \\
18 & S_lob & Spiny lobster & 0.37 & 0.85 & 1.15 & 0.07 & 1.22 \\
19 & Rhodo & Rhodophyta & 1.05 & 0.00 & 0,76 & 0.28 & 1.05 \\
20 & Phae & Phaeophyta & 1.05 & 0.00 & 0.76 & 0.28 & 1.05 \\
21 & Gerr & Gerreidae & 0.51 & 0.54 & 0.91 & 0.14 & 1.05 \\
22 & B_bra & Black brant & 0.09 & 0.74 & 0.80 & 0.03 & 0.83 \\
23 & Chlo & Chlorophyta & 0.13 & 0.00 & 0.11 & 0.02 & 0.13 \\
24 & Graywhales & Gray whales & 0.00 & 0.10 & 0.07 & 0.03 & 0.10 \\
\hline & & & & & & &
\end{tabular}


A

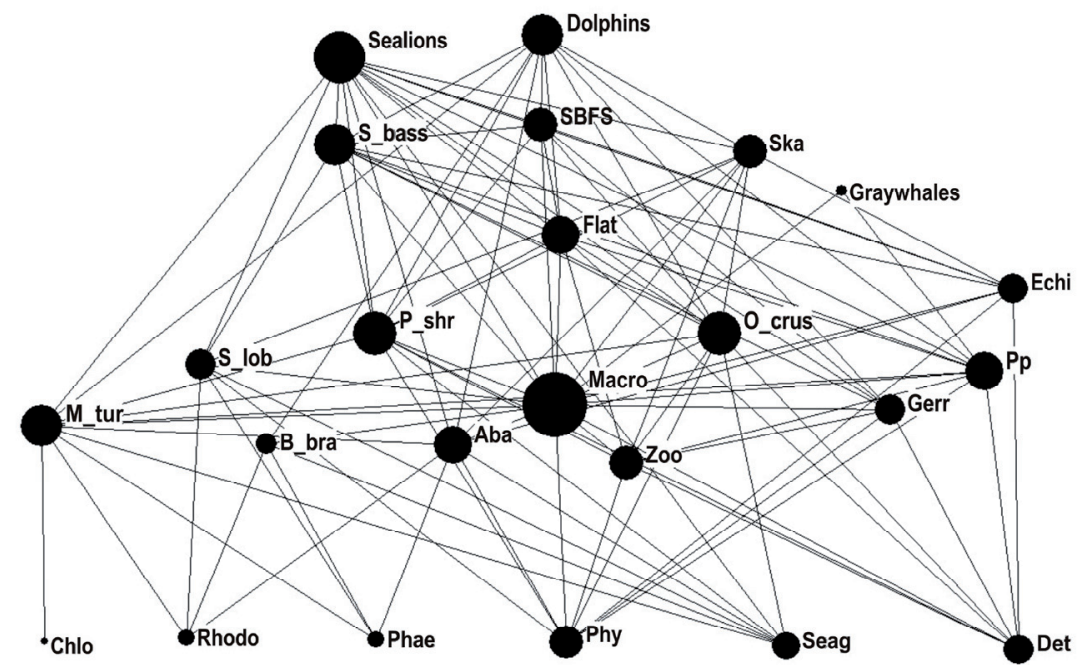

B

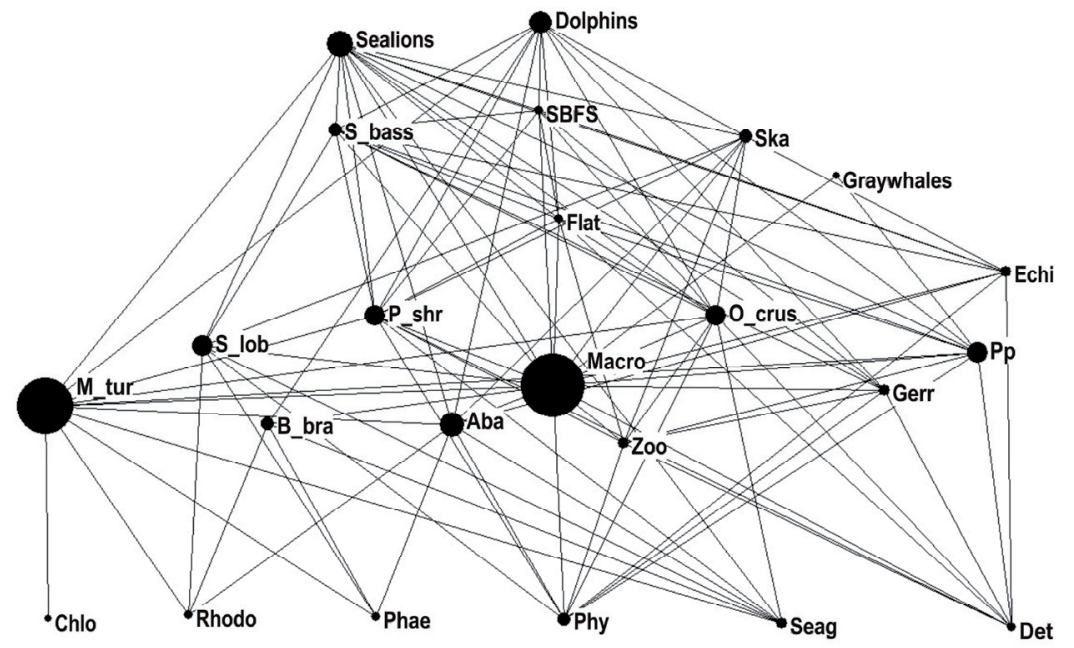

$\mathrm{C}$

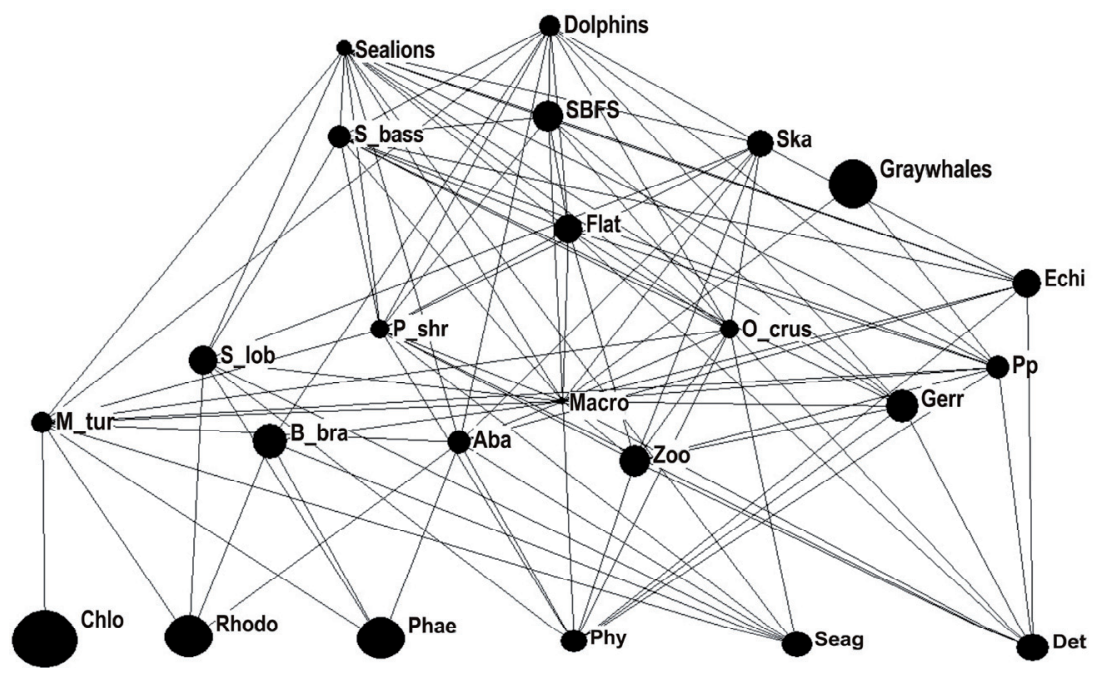

Figure 2. Topological indices of the trophic web in the study area. A) Node degree $(D)$, B) Betweenness centrality index $(B C), C)$ Closeness centrality index $(C C)$. The size of the nodes is proportional to $D$ and $B C$ and inverse to $C C$. Trophic component abbreviations are listed in Table 2. 

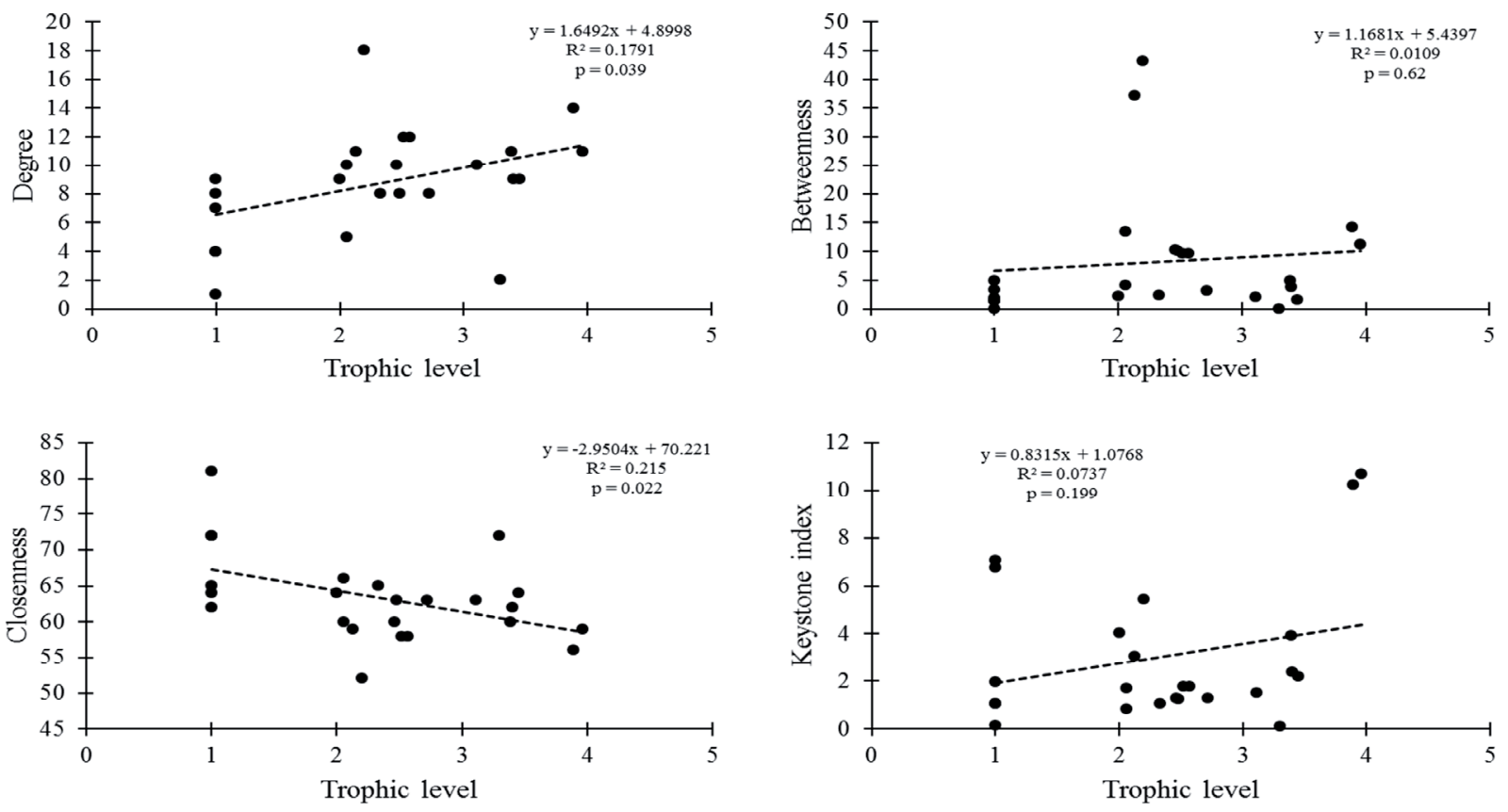

Figure 3. Relationships among the centrality indices, Degree $(D)$, Betweenness $(B C)$, Closeness $(C C)$ and Keystone index $(K)$, and trophic level of nodes in Bahía Magdalena, Mexico.

For the keystone index $(K)$, dolphins and sea lions showed the highest values. The black brant (Branta bernicla (L.)), Chlorophyta and gray whales exhibited the lowest topological importance values in the model (Table 2). Finally, analysis of key ecosystem groups using the KPP-2 algorithm indicated a single species, the pelagic red crab (Pleurocondes planipes Stimpson), exerts the most influence on trophic web interactions. The dispersion of this species' effect reaches $100 \%$ of web nodes.

When pooled centrality data were compared to trophic levels no trends were identified. However, the highest values of centrality $(D, B C$, and $C C)$ were present at intermediate trophic levels (Fig. 3).

\subsection{Other structural properties}

The total estimated connections in the system $(L)$ were 103 , with an average density of $L / S=4.2$. Other parameters were as follows: average length of the pathway $A L P=5$, fraction of basal groups $F B G=0.25$, fraction of intermediate groups $F I G=0.667$ and fraction of top groups $F T G=0.083$. The $G P / G D$ ratio estimated for Bahía Magdalena trophic web was 1.22 .

\subsection{Biomass balance model}

Total flow estimated for the Bahía Magdalena ecosystem (TSF) was $3361.4 \mathrm{tkm}^{2} \mathrm{yr}^{-1}$ of which $52 \%$ were destined for consumption, $26 \%$ for respiration processes, $19 \%$ for detritus, and $3 \%$ for export. The ratio between total flow of consumption $(Q)$ and the total flow of the trophic web $(T S F)$ was 0.50 , meaning that $50 \%$ of total flow maintains the organization of the web. The ratio between total primary production and total biomass (excluding that from detritus) was relatively high $(P P / T B=9.26)$, possibly indicating that the ecosystem has undergone eutrophication. The ratio between total primary production and total respiration $(P P / R)$ was 1.14 , which can be interpreted as a sign of low impact or low levels of eutrophication. The average omnivory index $(S O I)$ was 0.17 . The ascendancy was $22 \%$ of the development capacity, leaving an overhead (surplus) of $78 \%$.

\section{Discussion}

This research used two methodological approaches to analyze trophic web structure and function in the temperate coastal lagoon of Bahía Magdalena. Plagányi (2007) summarizes various modelling approaches currently used in ecosystems analyses of fisheries. Choosing an appropriate model depends not only on the research questions but also on logistical constraints such as labor and other costs. The two different approaches used to analyze the Bahía Magdalena trophic web were consistent and complementary, moreover we found similar values among some indicators obtained through different methods, as detailed below.

In terms of the number of functional group interactions, both node degree $(D)$, and connectance $(C)$, are within known ranges for trophic webs (Dunne 2009). Attributes of trophic web structure, such as skewed degree distributions (e.g., power law or exponential) are critical in maintaining biodiversity (Thompson et al. 2012). Results described here may reflect the incorporation of a few functional groups clustered at the base of the trophic web (Cruz-Escalona et al. 2013), which has been recorded in numerous studies of food webs 
Table 3. Comparative values of topological and ecological networks indices of Bahía Magdalena and other ecosystems. C=connectance, $\mathrm{L}=$ Link density, $\mathrm{FO}=$ fraction of omnivores, $\mathrm{FBG}=$ fraction of basal groups, $\mathrm{FIG}=$ fraction of intermediate groups, $\mathrm{FTG}=$ fraction of top groups. References are: 1= Navia et al. 2016; 2= López-García 2015; 3= Dambacher et al. 2010, 4= Yodzis 1998; 5= Opitz 1996; 6= Link 2002; 7= Gaichas and Francis 2008; 8= Dunne et al. 2002; 9= Martinez 1991; 10= Christian and Luczkovich 1999.

\begin{tabular}{|c|c|c|c|c|c|c|c|c|c|c|}
\hline References & Region & System & Location & \# Taxa & $\mathrm{C}$ & $\mathrm{L}$ & FO & FBG & FIG & FTG \\
\hline This study & Bahía Magdalena & Marine & Mexico & 24 & 0.19 & 4.2 & - & 0.25 & 0.667 & 0.083 \\
\hline 1,2 & Golfo de Tortugas & Marine & Colombia & 286 & 0.02 & 6.0 & - & - & - & - \\
\hline 3 & South western Pacific & Marine & Pacific Ocean & 109 & 0.01 & 1.9 & - & - & - & - \\
\hline 3 & Central-western Pacific & Marine & Pacific Ocean & 142 & 0.01 & 2.1 & - & - & - & - \\
\hline 3 & Central-eastern Pacific & Marine & Pacific Ocean & 91 & 0.02 & 2.4 & - & - & - & - \\
\hline 4 & West African coast & Marine & Benguela & 29 & 0.24 & 7.9 & - & - & - & - \\
\hline 5 & Small Caribbean reef & Marine & Virgin Islands & 50 & 0.22 & 11 & 0.88 & 0.06 & 0.94 & 0.00 \\
\hline 5 & Large Caribbean reef & Marine & Virgin Islands & 245 & 0.05 & 14 & 0.88 & 0.02 & 0.97 & 0.04 \\
\hline 6 & North-east US shelf & Marine & East coast of US & 79 & 0.22 & 18 & 0.89 & 0.25 & 0.94 & 0.37 \\
\hline 7 & Gulf of Alaska & Marine & Alaska & 406 & - & 2.6 & - & 0.14 & 0.82 & 0.35 \\
\hline 8 & Ythan Estuary & Estuarine & Scotland & 124 & 0.02 & 1.6 & - & - & - & - \\
\hline 9 & Little rock lake & Lake & USA & 92 & 0.11 & 10.8 & - & - & - & - \\
\hline 10 & St. Marks Seagrass & Seagrass & USA & 42 & 0.09 & 4.6 & - & - & - & - \\
\hline
\end{tabular}

(Link 2002). Results may therefore vary with the inclusion of more functional groups or a different level of aggregation, since groups at the base of the trophic web are sensitive to aggregation and diversity (Gauzens et al. 2013).

The topological approach results suggest that the structure of the trophic web depends primarily on lower and intermediate trophic level organisms, including macrobenthic invertebrates, penaeid shrimp and marine turtles, similar to results seen in marine food webs from other regions (Table 3). Sea lions appear to play an important ecological role in Bahía Magdalena, evident from their relatively high degree of centrality. A similar combination of species from upper and intermediate trophic levels appears to exert direct and indirect trophic effects in other tropical coastal marine trophic webs (Navia et al. 2010). These species appear to play major ecological roles that are distributed throughout different trophic levels of the food web, thus increasing web complexity and resilience to external pressures (Bascompte et al. 2005, Thompson et al. 2007).The relationship between topological importance and trophic level of each node shows that the nodes with the highest centrality values are located in intermediate trophic levels, consistent with results in Scotti and Jordan (2010). This is particularly reflected in the degree of the node $(D)$, betweenness $(B C)$ and closeness $(C C)$. Therefore, once again there is evidence that refutes the paradigm that directly relates the trophic level of one species with their importance in the network structure.

Although the mesoscale structure of the web is governed by organisms from intermediate and lower trophic levels, keystone index $(K)$ results show that trophic web control is top-down. Control specifically depends on sea lions, a species considered to be a top predator in the Bahía Magdalena ecosystem. This result is consistent with analyses of many other trophic webs (Libralato et al. 2006, Navia et al. 2010, 2016). The loss of such top predators could lead to a change in ecosystem trophodynamics (from top-down to bottom-up), since groups that follow the top predator in terms of their topologi- cal importance belong to intermediate and lower trophic levels. A web without top predators would likely be dominated by functional groups such as phytobenthos, detritus, small bottom feeding sciaenids, and macrobenthic invertebrates. This type of inverted biomass pyramid may represent a structural modification that precedes a new level of organization or change of state (Lotze et al. 2011). Because energy is lost through food chains, top carnivores are at risk from disturbance further down the food chain. If there is a reduction in the numbers of producers or primary consumers, existence of the top carnivores can be put at risk if there are not enough organisms (and therefore energy and biomass) to support them. Therefore, top functional groups may be the first ones to noticeably suffer through ecosystem disruption.

Libralato et al. (2006) previously described the emerging role of certain functional groups from the base of the trophic web in coastal marine ecosystems after the ecosystem was disturbed or altered, noting that some benthic groups can reach values associated with keystone roles. Lassalle et al. (2012) recently reported similar structural patterns in two ecosystems that differed both in terms of their actual physical structures (semi-closed vs. open basins), and performance criteria (levels of aggregation of different functional groups). These researchers emphasized the importance of pelagic and macrobenthic zooplankton in regulating the entire community.

For the Key Player Problem analysis, the optimal set of key players was determined by measuring fragmentation increase as nodes were removed from the network. The theoretical removal of pelagic red crab impacted, in only two steps, all nodes of the network, suggesting that the removal of this species significantly divided the network. This suggests that control of trophic web structure and interactions primarily is regulated for the invertebrates.

Aurioles-Gamboa et al. (1994) previously recognized the importance of the pelagic red crab in the functioning of the Bahía Magdalena trophic web, as well as the organism's 
extraordinary seasonal abundance. This suggests that trophic web structure and interactions are primarily regulated by the invertebrates. The extraordinary biomass volume of the pelagic red crab could generate changes in the ecosystem without drastically altering its structure and functionality. Other authors have described the high functional importance of benthic organisms (e.g., amphipods, polychaetes, infauna, etc.) in marine ecosystems of the Gulf of Mexico, also noting the biomass fraction they represent and its effects on energy flows (Soto and Escobar-Briones 1995).

Other structural properties of the Bahía Magdalena trophic web resemble those of previously studied ecosystems. The average length of the shortest pathway between all pairs of taxa ( $L / S=4.2$ connections) was nearly identical to other marine ecosystems (Dunne et al. 2004). The connectance value for Bahía Magdalena (0.19) was within value ranges for other marine ecosystems (0.01 - 0.24; Opitz 1996, Yodzis 1998, Link 2002, Gaichas and Francis 2008, Dambacher et al. 2010, López-García 2015, Navia et al. 2016). Recent research shows that average pathway length in aquatic ecosystems, as estimated through the analysis of food webs, resembles those expected from small world type webs (Navia et al. 2012, 2016). This means that no matter how different ecosystems are, they include a limited number of trophic levels through which energy can flow and differ only slightly in terms of their structural parameters (e.g., connectance and aggregation degree; Dunne et al. 2002).

Dunne et al. (2004) also observed that the density of connections $(L / S)$ and average pathway length changed drastically between trophic webs. This finding is consistent with current theories on trophic webs, since the parameters in question depend on the number of taxa in the web. In trophic webs composed of relatively few components (e.g., the upwelling ecosystem associated with the Benguela Current includes 29 taxa), connection densities will reflect these lower values $(L / S=7.9$ and $A L P=6.5$, Yodzis 1998). In ecosystems with more groups (e.g., the continental shelf of the northwestern United States includes 81 taxa), the estimated values are much higher $(L / S=18.1$ and $A L P=15.5$, Link 2002). Thus, the Bahía Magdalena food web showed lower values of diversity and density of links and higher values of connectance than other food webs with higher taxonomic resolution such as the Large Caribbean reef (Opitz 1996), Arctic (Bodini et al. 2009), Antarctic (Raymond et al. 2011) and the Colombian Pacific coast (López-García 2015, Navia et al. 2016; Table 3). Meanwhile, trophic networks that include few trophic groups such as Benguela upwelling (Yodzis 1998), small Caribbean reef (Opitz 1996) and the east coast of US (Link 2002) are more similar to results from Bahía Magdalena (Table 3).

The structural properties indicate a direct relationship between species richness and functional group fractions, wherein the fraction of basal and top components decreases and the fraction of intermediate species significantly increases as the overall number of groups in the trophic web increases (Thompson et al. 2012). In this regard, the trophic network of Bahía Magdalena showed similar values to those recorded in most marine food webs, with high fractions of intermediate species $(0.667)$ and a very low percentage of top predators
(0.083, Table 3). These results are consistent with the centrality indices found in this study, suggesting high structural importance of species in intermediate trophic levels as macrobenthic invertebrates, pelagic red crab, penaeid shrimps and green turtles.

Only certain trophic groups in the food web feed on prey from one single trophic level while several trophic groups feed at different trophic levels, (i.e., omnivores). The overall omnivory system index (SOI) for Bahía Magdalena, which is based on individual omnivory values, is relatively low but resides in the middle of the estimated range for various marine ecosystems in Mexico (Table 4 in Appendix 1). Low SOI values result from a large number of functional groups with more or less specialized diets. Villanueva et al. (2006) further noted that the balance between strong and weak interactions between functional groups within the ecosystem causes these low values. Similarly, Bascompte et al. (2005) related a higher degree of omnivory among the components to greater web structure strength and, as a result, greater capacity to buffer effects of possible trophic cascades.

Although omnivores were thought to be relatively rare in food webs (Pimm 1982), recent topological reconstructions of food webs have recognized them as key components of biological communities (Bascompte et al. 2005, Thompson et al. 2007). Early studies suggested an inherent instability in food webs with high levels of omnivory (Pimm 1982), but later studies have revised this view (Krivan and Diehl 2005). Empirical evidence of omnivore contributions to ecosystem stability remains controversial (Williams and Martinez 2004).

The ratio between total primary production and total biomass in Bahía Magdalena was high in comparison with many other coastal ecosystems (Appendix), possibly indicating that the ecosystem has undergone eutrophication. However, there are higher $P P / T B c o$ values reported for ecosystems with strong signs of environmental deterioration such as the Pearl River Delta estuary in China $(P P / T B C O=18.13$; Duan et al. $2009)$ and La Paz Bay ecosystem $(P P / T B c o=58.5$; ArreguínSánchez et al. 2007) in the southern of Gulf of California (Appendix). It is important to have caution when using the $P P / T B c o$ index as evidence of eutrophication signals. Particularly, in the Bahía Magdalena ecosystem CervantesDuarte et al. (2013) found no eutrophication signals from oceanographic and productivity data, results in contrast with the $P P / T B C O$ values estimated in this study. Estimates of the total biomass of the ocean differ, but it is generally acknowledged that this value does not exceed $1 \%$ of land biomass. However, the rate of its production is several orders higher in the ocean than on the continents: in particular, the ratio between annual production of marine phytoplankton and its biomass is about 300:1 whereas the average corresponding value for land vegetation is $0.07: 1$. A high rate of plankton reproduction permits the support of considerable biomass of organisms in upper trophic levels. Ocean areas differ significantly by their productivity. In general, coastal and estuarine waters are more fertile (Matishov 2009).

Similarly, the relatively low primary production to respiration ratio $(P P / R)$ for the Bahía Magdalena ecosystem can 
be interpreted as a sign of low impact or low levels of eutrophication. This index can also be used to evaluate damage caused by anthropogenic activities. During the initial phase of ecosystem development, the $P P / R$ should be $>1$ as production exceeds respiration. In contrast, systems subjected to organic contamination should have ratios $<1$. Finally, there is a balance between energy production and maintenance costs in mature systems; thus, the ratio is close to 1 in these cases (Odum 1971, Christensen et al. 2005). For example, in the Chiku lagoon (Taiwan Sea), an ecosystem with strong indications of environmental deterioration, a $P P / R$ of 15.5 has been reported (Lin et al. 1999, Appendix). This damage is suggested to be the result of run-off from the many rivers that drain into the Ckiku lagoon during the rainy season, carrying with them nutrients released by agricultural activities (Lin et al. 1999).

The two approaches used in this study described in a reasonable manner the structure and functioning of the food web ecosystem of Bahía Magdalena. The complexity of the structure and functioning of the food web of Bahía Magdalena can be summarized in three intrinsic features: a high production of phytoplankton, which is rarely used by primary consumers; a clear distinction between pelagic and benthic food chains in the first three trophic levels with a strong coupling between them; and high connectivity of a small number of functional groups. This study provides a theoretical and empirical framework for predicting functional responses of real ecosystems in times of structural change, and thus can facilitate more evidence-based approaches to ecosystem management.

Acknowledgments: We would like to thank P. Del MonteLuna for his valuable contributions in analysis and discussion of this manuscript, M. S. Peterson who provided useful comments on an early draft, and P. Kretchmer and N. J. Brown-Peterson for the assistance in editing the final document. This study was supported by IPN-SIP 20140234, IPN-SIP 20160 349, and SEP-CONACyT/2012/CB/180894. VHCE was supported by programs at the Instituto Politécnico Nacional: Estímulos al Desempeño de los Investigadores (EDI) and Comisión de Operación y Fomento de Actividades Académicas (COFAA).

\section{References}

Arreguín-Sánchez, F., del Monte-Luna, P., Díaz-Uribe, J.G., Gorostieta, M., Chávez, E.A. and Ronzón-Rodríguez, R. 2007. Trophic model for the ecosystem of La Paz Bay, Southern Baja California Peninsula, Mexico. In: Le Quesne, W.J.F., ArreguínSánchez, F. and Heymans, S.J.J. (eds.), INCOFISH Ecosystem Models: Transiting from Ecopath to Ecospace. Fisheries Centre, University of British Columbia, Fisheries Centre Research Reports 15(6). pp. 134-160.

Aurioles-Gamboa, D., Castro-González, M.I. and Pérez-Flores, R. 1994. Annual mass stranding of pelagic red crabs Pleuroncodes planipes (Crustacea: Anomura: Galatheidae), in Bahía Magdalena, Baja California Sur, Mexico. Fish. Bull. 92: 464470.
Bascompte, J., Melián, C.J. and Sala, E. 2005. Interaction strength combinations and the overfishing of a marine food web. Proc. Natl. Acad. Sci. USA 102: 5443-5447.

Bodini, A., Bellingeri, M., Allesina, S. and Bondavalli, C. 2009. Using food web dominator trees to catch secondary extinctions in action. Philos. Trans. R. Soc. Lond. B Biol. Sci. 364: 1725-1731

Borgatti, S.P., Everett, M.G. and Freeman, L.C. 2002. UCINET VI: Software for Social Network Analysis, Analytic Technologies, Harvard, US. 47 pp.

Borgatti, S.P. and Molina, J.L. 2003. Ethical and strategic issues in organizational network analysis. J. Appl. Behav. Sci. 39(3): $337-350$.

Borgatti, S.P. and Foster, P. 2003. The network paradigm in organizational research: A review and typology. J. Manag. 29(6): 991-1013.

Cervantes-Duarte, R., Prego, R., López-López, S., Aguirre-Bahena, F. and Ospina-Alvarez, N. 2013. Annual patterns of nutrients and chlorophyll in a subtropical coastal lagoon under the upwelling influence (SW of Baja-California Peninsula). Estuar. Coast. Shelf. Sci. 120: 54-63.

Christensen, V., Walters, C. and Pauly, D. 2005. Ecopath with Ecosim: A User's Guide. Fisheries Centre, University of British Columbia, BC, Vancouver.

Christensen, V., Walters, C. 2004. Ecopath with Ecosim: methods, capabilities and limitations. Ecol. Model. 172:109-139.

Christian, R.R. and Luczkovich, J.J. 1999. Organizing and understanding a winter's seagrass food web network through effective trophic levels. Ecol. Model. 117: 99-124.

Cruz-Escalona, V.H., Arreguín-Sánchez, F. and Zetina-Rejón, M. 2007. Analysis of the ecosystem structure of Laguna Alvarado, western Gulf of Mexico, by means of a mass balance model. Estuar. Coast. Shelf. Sci. 72: 155-167.

Cruz-Escalona, V.H., Morales, M.V., Navia, A.F., Rodríguez-Barón, J.M. and del Monte-Luna, P. 2013. Análisis funcional de la red trófica de Bahía Magdalena, Baja California Sur, México. Lat. Am. J. Aquat. Res. 41(3): 519-543.

Dambacher, J.M., Young, J.W., Olson, R.J., Allain, V., GalvánMagaña, F., Lansdell, M.J., Bocanegra-Castillo, N., AlatorreRamírez, V., Cooper, S.P. and Duffy, LM. 2010. Analyzing pelagic food webs leading to top predators in the Pacific Ocean: A graph-theoretic approach. Prog. Oceanogr. 86: 152-165.

Duan, L.J., Li, S.Y., Liu, Y., Jiang, T. and Failler, P., 2009. A trophic model of the Pearl River Delta coastal ecosystem. Ocean. Coast. Manage. 52: 359-367.

Dunne, J.A. 2006. The network structure of food webs. In: Pascual, M., Dunne, J.A. (eds.), Ecological Networks: Linking Structure to Dynamics in Food Webs. Oxford University Press, New York, US. pp. 27-86.

Dunne, J.A. 2009. Food webs. In: Meyers, R.A. (ed.). Encyclopedia of Complexity and Systems Science. Springer, New York, US. pp. 3661-3682.

Dunne, J.A., Williams, R.J. and Martinez, N.D. 2002. Network structure and biodiversity loss in food webs: robustness increases with connectance. Ecol. Lett. 5: 558-567.

Dunne, J.A., Williams, R.J. and Martinez, N.D. 2004. Network structure and robustness of marine food webs. Mar. Ecol. Progr. Ser. 273: 291-302.

Estes, J.A., Crooks, K. and Holt, R. 2001. Predators, ecological role of. In: S.A. Levin (ed.), Encyclopedia of Biodiversity. Academic Press, San Diego, California, US. pp. 857-878. 
Finn, J.T. 1976. Measures of ecosystem structure and function derived from analysis of flows. J. Theor. Biol. 56: 363-380.

Funes-Rodríguez, R., Gómez-Gutiérrez, J. and Palomares-García, R. (eds.). 2007. Estudios Ecológicos en Bahía Magdalena. Gobierno del Estado de Baja California Sur, Secretaría de Turismo de Baja California Sur, Fondo para la Protección de los Recursos Marinos de Baja California Sur, Instituto Politécnico Nacional, Centro Interdisciplinario de Ciencias Marinas. CICIMAR-IPN, La Paz, Baja California Sur, México.

Gaichas, S.K. and Francis, R.C. 2008. Network models for ecosystem-based fishery analysis: a review of concepts and application to the Gulf of Alaska marine food web. Can. J. Fish. Aquat. Sci. 65: 1965-1982.

Gauzens, B., Legendre, S., Lazzaro, J. and Lacroix, G. 2013. Foodweb aggregation, methodological and functional issues. Oikos. 122: 1606-1615.

Hall, S. J., Raffaelli, D.G. 1991. Food web patterns: lessons from a species-rich web. J. Anim. Ecol. 60:823-839.

Heymans, J.J., Coll, M., Libralato, S., Morissette, L. and Christensen, V. 2014. Global patterns in ecological indicators of marine food webs: A modelling approach. PLoS ONE. 9(4): e95845.

Jordán, F., Liu, W. and Davis, A.J. 2006. Topological keystone species: measures of positional importance in food webs. Oikos. 112: $535-546$

Jordán, F., Okey, T.H., Bauer, B. and Libralato, S. 2008. Identifying important species: linking structure and function in ecological networks. Ecol. Model. 216: 75-80.

Krivan, V. and Diehl, S. 2005. Adaptive omnivory and species coexistence in tri-trophic food webs. Theor. Pop. Biol. 67: 85-99.

Lassalle, G., Gascuel, D., Le Loch, F., Lobry, J., Pierce, G.J., Ridoux, V., Santos, M.B., Spitz, J. and Niquil, N. 2012. An ecosystem approach for the assessment of fisheries impacts on marine toppredators: the Bay of Biscay case study. ICES J. Mar. Sci. 69: 925-938.

Libralato, S., Christensen. V. and Pauly, D. 2006. A method for identifying keystone species in food web models. Ecol. Model. 195: 153-171.

Lin, H.J., Shao, K.T., Kuo, S.R., Hsieh, H.L., Wong, S.L., Chen, I.M., Lo, W.T. and Hung, J.J. 1999. A trophic model of a sandy barrier lagoon at Chiku in southwestern Taiwan. Estuar. Coast. Shelf. Sci. 48: 575-588.

Link, J. 2002. Does food web theory work for marine ecosystems? Mar. Ecol. Prog. Ser. 230: 1-9.

Lluch-Belda D., Elorduy-Garay J., Lluch-Cota S.E. and PonceDíaz, G. (eds.), 2000. BACs, Centro de Actividad Biológica del Pacifico Mexicano. CIBNOR SC, CICIMAR-IPN, CONACyT, La Paz, Baja California Sur, México.

López-García, J. 2015. Características estructurales y funcionales de la red trófica marina costera de la zona central del Pacífico colombiano. M.Sc. Thesis, Universidad del Valle, Cali, Colombia.

Lotze, H.K., Coll, M. and Dunne, J.A. 2011. Historical changes in marine resources, food web structure and ecosystem functioning in the Adriatic Sea, Mediterranean. Ecosystems. 14: 198-222.

Martinez, N. 1991. Artifacts or attributes? Effects of resolution on the Little Rock Lake food web. Ecol. Monogr. 61(4): 367-392.

Matishov, G.G. 2009. Effects of Global Warming on Marine Ecosystems. In: Yotova, A. (ed.), Climate Change, Human Systems and Policy. EOLSS Publishers, Paris, France. pp. 188204.

May, R.M. 1972. Will a large complex system be stable? Nature 238: $413-414$.
Morales-Zárate, M.V., Arreguín-Sanchez, F., Lopez-Martinez, J. and Lluch-Cota, S.E. 2004. Ecosystem trophic structure and energy flux in the Northern Gulf of California, México. Ecol. Model. 174: 331-345.

Navia, A.F., Cortés, E. and Mejía-Falla, P.A. 2010. Topological analysis of the ecological importance of elasmobranch fishes: A food web study on the Gulf of Tortugas, Colombia. Ecol. Model. 221: 2918-2926.

Navia, A.F., Cortés, E., Jordán, F., Cruz-Escalona, V.H. and MejíaFalla, P.A. 2012. Changes to marine trophic networks caused by fishing. In: Mahamane, A. (ed.), Diversity of Ecosystems. InTech, Croatia, pp. 417-452.

Navia, A.F., Cruz-Escalona, V.H., Giraldo, A. and Barausse, A. 2016 The structure of a marine tropical food web, and its implications for ecosystem-based fisheries management. Ecol. Model. 328: $23-33$.

Odum, H.T. 1971. Environment, Power and Society. John Wiley \& Sons, New York.

Opitz, S. 1996. Trophic interactions in Caribbean coral reefs. ICLARM Tech Rep 43. Manila, Philippines.

Pauly, D., Soriano, M. and Palomares, M.L. 1993. Improved construction, parametrization and interpretation of steady state ecosystem models. In: Christensen, V. and Pauly, D. (eds.), Trophic Models of Aquatic Ecosystems. ICLARM Conference Proceedings 26, Manila, Philippines. pp. 1-13.

Perdomo, G., Thompson, R. and Sunnucks, P. 2012. Food Web: An Open-Source Program for the Visualisation and Analysis of Compilations of Complex Food Webs. http://cran.r-project.org/ web/packages/foodweb/.

Pimm, S.L. 1982. Food Webs. Chapman \& Hall. London, UK.

Plagányi, E.E. 2007. Models for an Ecosystem Approach to Fisheries. FAO Fish Technical Paper, 477: 107.

Polis, G.A. and Strong, D.R. 1996. Food web complexity and community dynamics. Am. Nat. 147: 813-846.

Raymond, B., Marshall, M., Nevitt, G., Gillies, C.L., van den Hoff, J., Stark, J.S., Losekoot, M., Woehler, E.J. and Constable, A.J. 2011. A Southern Ocean dietary database. Ecology. 92: 1188.

Scotti, M. and Jordán, F. 2010. Relationships between centrality indices and trophic levels in food webs. Community Ecol. 11: 59-67.

Soto, L.A. and Escobar-Briones, E. 1995. Coupling mechanisms related to trophic benthic production in the SW Gulf of Mexico. In: Eleftheriou, A., Ansell, A.D. and Smith, C.J. (eds.), Proceedings of 28th European Marine Biology Symposium. Institute of Marine Biology of Crete, Crete, pp. 233-242.

Thompson, R.M., Hemberg, M., Starzomski, B.M. and Shurin, J.B. 2007. Trophic levels and trophic tangles: the prevalence of omnivory in real food webs. Ecology 88: 612-617.

Thompson, R.M., Brose, U., Dunne, J.A., Hall, R.O. Jr, Hladyz, S., Kitching, R.L., Martinez, N.D., Rantala, H., Romanuk, T.N., Stouffer, D.B. and Tylianakis, J.M. 2012. Food webs: reconciling the structure and function of biodiversity. Trends Ecol. Evol. 27(12): 689-97.

Ulanowicz, R.E. 1986. Growth and Development: Ecosystem Phenomenology. Springer-Verlag, New York.

Ulanowicz, R.E. 2004. A synopsis of quantitative methods for ecological network analysis. Comp. Biol. Chem. 28 (5-6): 321-339.

Villanueva, M.C., Laleye, P., Albaret, J.J., Lae, R., de Morais, L.T. and Moreau, J. 2006. Comparative analysis of trophic structure and interactions of two tropical lagoons. Ecol. Model. 197: 461-477. 
Williams, R.J. and Martinez, N.D. 2004. Food webs: Theory and data limits to trophic levels and omnivory in complex. Am. Nat. 163(3): 458-468.

Yodzis, P. 1998. Local trophodynamics and the interaction of marine mammals and fisheries in the Benguela ecosystem. J. Anim. Ecol. 67: 635-658.

Zetina-Rejón, M., Arreguín-Sánchez, F. and Chávez, E.A. 2003. Trophic structure and flows of energy in the HuizacheCaimanero lagoon complex on the Pacific coast of Mexico. Estuar. Coast. Shelf. Sci. 57: 803-815.

Received December 2, 2015 Revised March 31, April 29, 2016

Accepted June 13, 2016

\section{Appendix}

Ecological indicators sensu Ulanowicz (1986, 2004) used to compare the functional attributes of the Laguna Bahía Magdalena, Mexico model with other worldwide coastal ecosystem models.

The file may be downloaded from www.akademiai.com. 